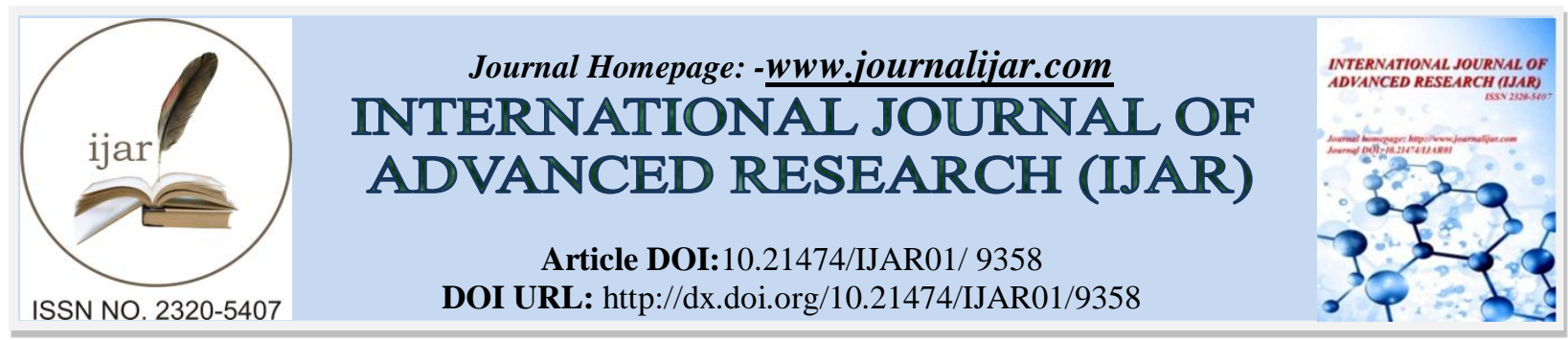

RESEARCH ARTICLE

\title{
INFLUENCE OF VERNACULAR ARCHITECTURE IN ENVIRONMENTAL RESPONSIVE BUILDINGS: A CASE STUDY OF ABUJA RESIDENTIAL DEVELOPMENTS.
}

Fatima Baba Ciroma, Aminu -Umar Wali Aisha and Stephen Zemo Audu.

Department of Architecture, College of Environmental Studies Kaduna Polytechnic. Kaduna, Nigeria.

\section{Manuscript Info}

Manuscript History

Received: 06 May 2019

Final Accepted: 08 June 2019

Published: July 2019

Key words: -

Vernacular architecture, Environment, Buildings, Materials.

\begin{abstract}
This paper examined influence of Vernacular Architecture in Environmental Responsive buildings. The aim of this study is to design a framework-based architecture that directly responds to environmental problems such as contextuality of design that creates physical and even psychological discomfort in buildings. The research design entails a fully-fledged design proposal based on an initial investigation from a pilot study of environmental responsive buildings through a combination of structured interviews of allied professionals and users to come up with answers to some research questions. The study adopts a Case study research methodology which captures the complexity of a single case with a view to understanding general principles of a phenomenon such as safety and security in the built environment. It can therefore be concluded that environmentally responsive design is an integrated approach that involves the use of natural practices in design to reduce energy consumption and cost, by appropriating the right construction practices and materials in context to the climate with proper use of local resources therefore, using the sustainable materials within the context of a place can reduce and play an important role in terms of economy and thermal emission of unwanted gas generated from the mechanized system. In addition to all these various viewpoints and studies, there is the concept of developmental vernacular architecture. The study recommended that If we consider this as a new classification in the approach to vernacular studies, it may therefore be considered a relatively new approach. If, however, one carefully considers the term "development," it is arguable that this is simply a basic characteristic of vernacular buildings, and therefore it seems peculiar to describe developmental vernacular as if it is separate from vernacular architecture as a whole
\end{abstract}

Copy Right, IJAR, 2019, All rights reserved.

\section{Introduction:-}

Derived from the Latin root vernaculus, the term vernacular was first used in England in 1839, and later gained wider use in the 1950's. Therefore, it is a rather new term. It is a phrase that has been used in a linguistic study to describe an indigenous idiom- a common speech. Paul Oliver explains, based on the linguistic use of the term that vernacular architecture may be understood as "the common speech of building. 
An understanding of vernacular processes enhances the understanding our own built environment and the architectural and cultural patterns of those outside our own. Vernacular forms and the aesthetic values adhered to are parts of our language of symbols of social consequence. These symbols become critical instruments of personal and community identity, and in fact serve as justification for, or factors of, social orders. The difficulty lies in the observer's ability, or lack of ability, to overcome the restraints of the orders and preconceived notions from his or her own culture. Exploration and analysis of these symbols also relate to people's methods of architectural communication, and the aesthetic values that may be perceived. Ethnographic studies, giving equal weight to intention and response and their interaction, provide a description, if only a narrative, of how the architectural language of a group employs both utilitarian and aesthetic values, and attempts to understand what meaning these values produce. This brings out the very important distinction of the non-functional significance of vernacular architectures; With a reversed relationship, modern design style that is developing recently, according to Prianto et al (2000), tends to be more universal and neglects the nature and its environment.

Prianto, et al further went ahead to mention that it is the designer's task to cooperate with urbanClimatologists and related experts to bear a comprehension about microclimate of immediateSurrounding before applying it on their design. To address climatic problems, architecturalParameters such as surrounding socio-physical features, building materials and orientation, Fenestrations, roof shape, building performance and landscape must be considered seriously.

Climate modification is also effective to obtain optimal thermal comfort in building and to achieveEnvironmentally responsive design.

The study will also look into how the idea of environmentally responsive design can be achieved that is through the concept of Critical Regionalism as a design theory to create an environmentally response design in Abuja metropolis and Nigerian macro-climate in general.

\section{Background of Study}

In the present era of building industry in Nigeria, architecture of the old age was set-aside in the sense that people used the indigenous building materials available within their context to construct their domiciliary habitat in order to achieve thermal comfort in a hot humid climatic area. However due to globalization influences such as technology, nowadays houses are being designed and built without considering the climatic condition of the location; by total utilization of active energy rather than traditional passive strategies (such as courtyard design) that have worked efficiently before. Certainly, the most obvious example may be the work of Hasan Fathy in the New Gourna village of Egypt. Seeking a self-reliant system of building which would be based on local material, process, Fathy attempted to produce not only a pleasing architecture but also a valuable process based on local patterns. His work has been criticized for being too focused on the aesthetic product and losing site of the community participation, yet it is still a valuable step towards the awakening of this new concept.

\section{Problem Statement}

Environmentally responsive design according to Ansah and Bamfo - Agyei (p. 317, 2012) is anIntegrated approach that involves the use of inspiration from environmental features and naturalPractices in design to reduce energy consumption and cost, by appropriating the right constructionPractices and materials in context to the climate with proper use of local resources.

The process of creating healthy and sustainable homes starts at the design stage. Securing a house is one of the most important aspects of creating a quality living for human's life. Nowadays, designs of private houses are being planned in a geographical location that is very hot and humid like Abuja without considering the climate and sustainable construction materials that adapt to the location.

According to Daroda (2011) in his citation of Yannas (2003) defines environmental responsive Architecture as architecture that scopes to accomplish occupant physio-thermal and visual comfortWith insignificant or no use of non-renewable resources by incorporating the elements of the local Environment effectively. He further termed it as Architecture that lowers any negative effect on the environment and is able to maintain the ecosystem of which it is a part of Residential housing is supposed to be environmentally responsive, meaning the built environment can respond and reflect the culture or environment of those people living in that society (Nigeria in this case). The culture here in this aspect refers to the way a user group terms and expresses its identity whether through values 
shared, behaviors, language or other methods. Houses are being built without adequately responding to the climate, building orientation, materials etc. Moreover, architects forget to use the basic building resources available in the context, and this will lead to discomfiture within the surrounding since the use of a mechanical cooling system is not $100 \%$ fully active due to the lack of steady electricity.

Nigerian traditional architecture has a unique sustainable approach. Its building materials satisfy the basic requirements of sustainable utilization of environmental resources (Odebiyi et al, 2010, p. 752).

\section{Aim}

To design a framework-based architecture that directly responds to environmental problems such as contextuallity of design that creates physical and even psychological discomfort in buildings.

\section{Objectives}

1. To use modern materials in context with climate to achieve an environmentally responsive Architecture.

2. To examine the problems and application of strategies, promote a holistic method of environmentally responsive design that is sympathetic with all the physical and Sociocultural demands of places (e.g. climate, topography).

3. To enhance an indoor-outdoor relationship of buildings and to ensure physical comfort (Ventilation, lighting etc.)

4. To establish an environmentally responsive design criterion for sustainable residential Building performance in Nigeria.

\section{Research Question}

1. What are the modern materials to be used to achieve an environmentally responsive architecture?

2. What is the method to be used in the examination of the problems?

3. What is the indoor-outdoor relationship of building?

4. What is the type of environmentally responsive design framework to be adopted for sustainable residential building performance in Nigeria?

\section{Research Argument}

This study will argue from a post-structural (critical regionalism) theory that environmental

Responsive design could be used to create a better and more qualitative housing in Abuja or Nigeria In general.

\section{Literature Review}

\section{Tropical Architecture}

Tropical architecture used as a description of modernist architecture in Africa, had its birth in British West Africa, comprising Nigeria, Sierra Leone, and the Gambia at the end of the Second World War time, (Uduku, 2006, p. 1).

Architectural design of residential building used to be developed by accumulated observation fromImmediate surroundings. Design without designer method passed on from one generation to theOther. Conversely, contemporary design style that is developing recently tends to be more universal and ignores the nature and its environment. (Prianto, et al 2000).

He also asserts that it is the architects' job to cooperate with urban climatologists and related experts to bear a comprehension about microclimate of immediate surrounding before applying it On their design. To face climate problem, architectural parameters such as building orientation, Window opening, roof shape, building performance and vegetation planning must be consideredSeriously, climate modification is also effective to obtain optimal temperature in building.

Tropical architecture is all about constructing and designing buildings in the tropics to comfort theClimate around the surrounding, tropical structures can be designed to comfort through the use ofPassive design elements like sunshades, cavity walls, light shelves, overhangs, roof and wallInsulation and even shading from large trees to block the sun.

\section{Vernacular Architecture}

Vernacular architecture is a product of an evolutionary process of self-correction which is often associated with but not confined to mud houses and thatch roofs, indeed far from the suggested 'primitive form of design, lacking 
intelligent thought', that it was once perceived as. Vernacular buildings are born out of local building materials, technology and architecture that are climate responsive and a reflection of the customs and lifestyles of a community. The typical vernacular forms of a building are in response to an environment: a sloping roof surface to bear the rainfall or a circular house form to combat cyclonic winds. According to Kazimee, "vernacular architecture represents more than a nostalgic longing for things and ways that have essentially become obsolete, but rather a learning method by which new global challenges can be addressed, which are global warming, housing crises, and economic equality" (2008:6).

Looking at the Nigerian perspective of it, the architecture transformed gradually when the colonial masters departed. The materials predominantly used around the northern area of the country are; earth, mud, adobe, stone combined with timber mostly from palm trunks, straw bales, coconut, and grass thatch. These materials were abundantly available in the area. The buildings constructed from these materials seemed to be more in harmony with the prevailing climate and they provided comfortable interiors regardless of exterior solar radiations (Opaluwa et al, 2012, p. 102).

Inventing an aesthetics view with these materials can be a bit hard but introducing the contemporary materials and merging them along will generate a distinctive model and at the end providing a good thermal comfort.

\section{Formal Housing}

According to Pugh (2000 quoted in Sivam, 2003), developing countries have three types of housing development systems - formal, informal and organic. Formal housing developments have the legal basis of the planning agency. These are developed within the structure of government rules, controls and regulations. Informal housing development is illegal and consisted of unauthorized 'colonies and squatter settlements. These types of developments happen mostly because of non-affordability or sometimes unavailability of housing in legal housing market. Organic housing development is mainly emerged over a period of time without any conscious measures legal or illegal. Old cities and urban villages are of examples of these types of developments. However, organic housing is often treated also as informal housing depending on its diversity, complexity and widespread nature.

\section{Influence of Globalization}

Globalization intruded this argument because of how it affected the Nigerian culture gradually. And culture is a way of life of a certain society, furthermore it came into existences because it is how the evolution of homes hinders the changes from the normal architectural identity of the country to the western style of designs.

Anthony Giddens describes globalization as a homogenizing process, made possible by theDifferentiation of time from space. In this way, modernization establishes a network of global Relations between near-by and distant communities (Giddens, 1998).

Consent that globalization in some ways has affected the culture of Nigerians settings, affecting And/or change in contemporary architecture of residential domiciliary habitat from the existing Traditional art and architecture by establishing or designing the 'western world architecture' because of the attracting taste and aesthetics. Also due to the advent of technological construction materials and component in architecture, such as fans, air conditions etc. we tend to ignore the basic requirements in design such as positioning the fenestration where it is supposed to be, openings of the windows, room heights, because the air condition can serve the purpose without thinking the other way round.

\section{Climate responsive architecture}

Climate responsive architecture can be defined as architecture aimed at achieving occupant thermal and visual comfort with little or no recourse to non-renewable energy sources by incorporating the elements of the local climate effectively (Yannas, 2003). This refers therefore to architecture that reduces the negative impact on the environment and sustains the eco system of a given place. There are two main drivers of responsive design. These are the temperature and the solar geometry. With the information on temperature strategies for passive cooling or heating can be established while the solar geometry aids in the development of built forms, fenestration and shading. Within this however the winds, precipitation and humidity must also be considered as they play significant role in the comfort level of the occupants. 


\section{Methodology: -}

The study methodology is clear-cut. It would involve a combination of methods and strategies thatAre interrelated and work in harmony to critically investigate, examine and inevitably propose solutions to the research problem. The research will aim to develop a fully-fledged design proposal based on an initial investigation from a pilot study of environmental responsive buildings through a combination of structured interviews of allied professionals and users to come up with answers to the following questions, what is vernacular architecture to them? What guides their design philosophies? What guides occupants' design choices? To what level do they consider vernacular architecture in their design? And what the barriers of adopting vernacular architecture might be?

The answers to these questions will be synthesized to guide a focus group discussion. The output of the above will be used to formulate a framework that will be validated in an iterative process with more focus group discussions. The figure 1 . below shows a summary of the proposed methodology adopted for this research.

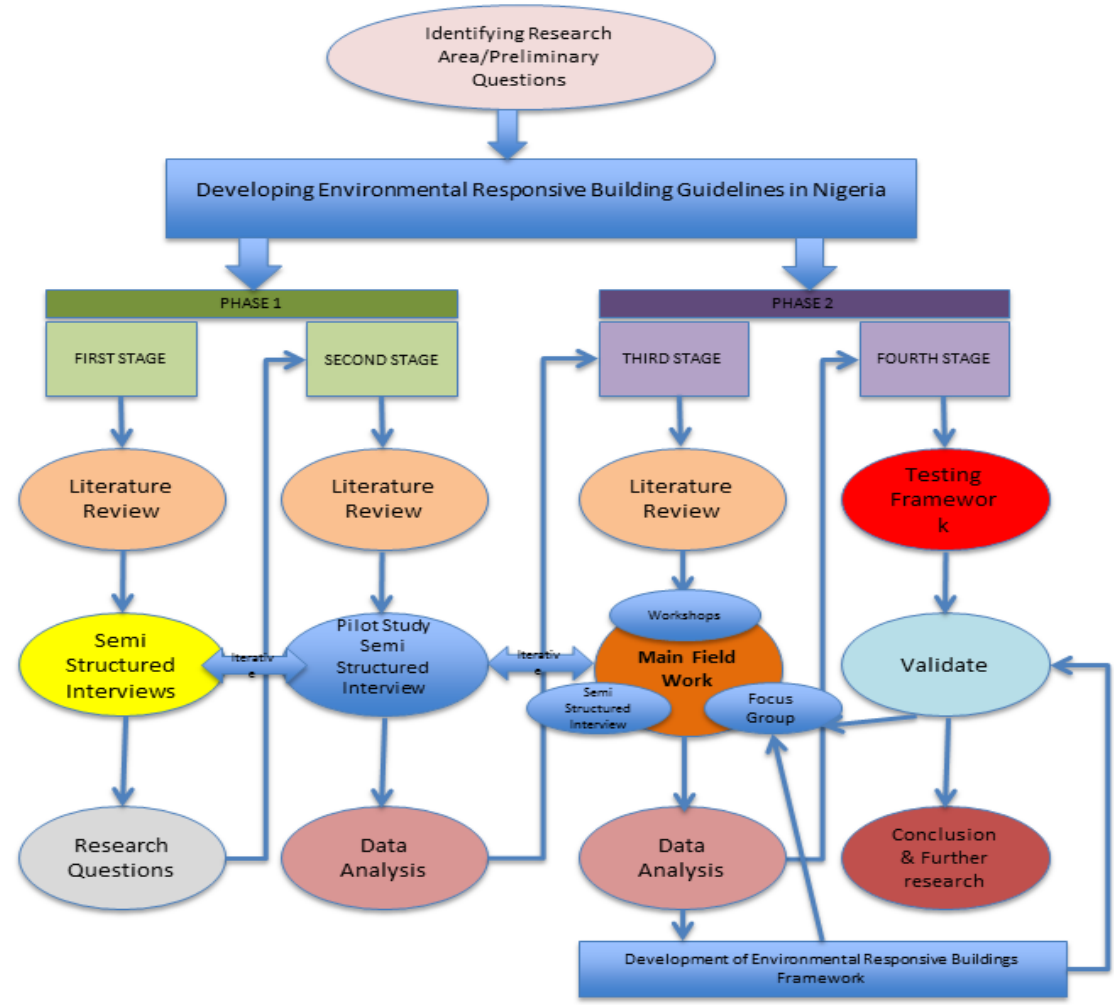

Research framework: source: author

\section{Case Study}

Based on the justifications that necessitated this study bordering around the inefficacy ofCurrent trends in design in sub-Saharan Africa; i.e. designs and subsequent buildings do not Respond to the environment, thus creating problems such as in contextually and discomfort, This study proposes to have a look at the city of Abuja, Nigeria as a didactic indicator that Typifies other areas in Nigeria and sub-Saharan Africa - south of the equator- because they Share all the main characters in weather, climate, and even culture. This approach is employed in the evaluation of the capacity of in cooperating vernacular architecture to effectively mitigate inclement weather. Cases of formal housing are assessed in terms of its climatic response factors such as location, building form, shading devices and materials. Sources of data include field observation, secondary data. Data collection analysed using content analysis and grounded theory where themes of climatic responsiveness is carefully coded strategically. Case study research method involves comprehensive study of a phenomenon over time within its natural setting in one or a few sites. It attempts to answer who, how, why and less of what research questions (Yusuf, 2013). 
Case Study methodology is applied not only in the social sciences, such as psychology, sociology, anthropology, and economics, but also in practice-oriented fields such as environmental studies, social work, and education and business studies. Case study research methodology captures the complexity of a single case with a view to understanding general principles of a phenomenon such as safety and security in the built environment.

There are different ideas about what a case study is. Case study should have a case that is the object of study. A case should be a complex functioning unit, be investigated in its natural context with a multitude of methods and be contemporary. As a form of research, case study is defined by interest in individual cases, not by the methods of inquiry used. Other researchers, such as Robert Yin (1994), place more emphasis on the method and the techniques that As Ansah and Bamfo-Agyei (2012) opined, environmentally responsive design is an integrated approach that involves the use of natural practices in design to reduce energy consumption and cost, by appropriating the right construction practices and materials in context to the climate with proper use of local resources. Using the sustainable materials within the context of a place can reduce and play an important role in terms of economy and thermal emission of unwanted gas generated from the mechanized system. In addition to all of these various viewpoints and studies, there is the concept of developmental vernacular architecture. If we consider this as a new classification in the approach to vernacular studies, it may therefore be considered a relatively new approach. If, however, one carefully considers the term "development," it is arguable that this is simply a basic characteristic of vernacular buildings, and therefore it seems peculiar to describe developmental vernacular as if it is separate from vernacular architecture. Rather, the term development, in this context, is meant to describe the human act of improving, or attempting to improve, well-being.

\section{Constitute a case study.}

The essence of case study methodology is triangulation, the combination on different levels of techniques, methods, strategies, or theories. The combination of qualitative and quantitative approaches is well established in case studies, but nonetheless, the differing quality standards - regarding truth, applicability, consistency, and neutrality - in qualitative and quantitative research are difficult to codify.

\section{Theory (Critical Regionalism)}

Leach (2010) surmises Critical Regionalism as — not a movement, as per Frampton's argument — but a paraaesthetic thought beyond just the descriptive, but also the prescriptive, that has certain traits of high modernism, and by so doing, does so in a way that transcends the simplistic thoughts of modernism such as the Avánt gardé, but goes to the extent of looking at the peculiarities and specificity of places/events such as contextual topography, geography, trado-cultural appropriations et al.

In as much every novel theory carved out of modernism presupposes the ideas of indoctrinating specificity to modernism, Critical Regionalism, through its applications seen in Maxwell Fry and Jane Drew's practice in parts of Nigeria and the Gold Coast, have to a great extent successfully negotiated this strategy in solving climatic problems through passive shading techniques and even orientation of the building.

Thus, there is no better appropriate theory that best suits and satisfies the aim and objectives of this study, since it relies on the application of environmentally empathetic methods in solving the problems discussed.

\section{Design}

Through the in-depth examination and analysis of these strategies afore-discussed, part of the methodologies would propose the use of design concepts and theories to test-run the proposed solutions to the problems based on the outcomes of the overall research. 


\section{Bibliography:-}

1. Agboola, O. P. (2011). Importance of climate to Architectural designs in Nigeria. Journal Environmental issues and Agriculture in developing countries, Vol. 3, No. 1

2. Ansah, S. K., and Bamfo - Agyei, E. (2012). "Minimization of Heat Gains in Buildings: The Case of Domestic Buildings in Cape Coast Metropolis - Ghana". p. 317

3. Cardinale, N., Rospi, G. and Stefanizzi, P. (2013) "Energy and microclimatic performance of Mediterranean vernacular buildings: The Sassi district of Matera and the Trulli district of Alberobello," Build. Environ., vol. 59, no. null, pp. 590-598.Daroda, K. S. (2011). "Climate responsive architecture: creating greater design awareness among architects". Journal of Environmental Issues and Agriculture in Developing Countries, Volume 3 No 1

4. Giddens, A. (1998). Modernliğin sonuçları. İstanbul: Ayrıntı Yayınları. pp. 66-67.

5. Leach, N. (2010) "Rethinking Architecture: a reader in cultural theory" (Ed.) London and New York, pp. 247 248

6. Odebiyi, S., Subramanian, S.O. and Braimoh, A. K. (2010) "Green Architecture: Merits for Africa (Nigerian Case Study)". Journal of Alternative Perspectives in the Social Sciences. Vol. 2, No 2,746-767.

7. Koenigsberger, O., H., Ingersoll, T. G., Mayhew, A. and Szokolay, S., V. (1975). Manual of Tropical Housing and Building: Climate Design. University Press. London.

8. Opaluwa, E., Obi, P., and Osasona, O. C. (2012). "Sustainability in traditional. African architecture: a springboard for sustainable urban cities". Sustainable Futures: Architecture and Urbanism in the Global South Kampala, Uganda, p. $27-30$.

9. Prianto, E., Bonneaud, F., Depecker, P. and Peneau, J. P. (2000). Tropical-Humid Architecturein Natural Ventilation Efficient Point of View.

10. Prianto, E., Bonneaud, F., Depecker, P. and Peneau, J. P. (2000). Tropical-Humid Architecture inNatural Ventilation Efficient Point of View.

11. Uduku, Ola. (2006). "Modernist architecture and 'the tropical' in West Africa: Thetropical architecture movement in West Africa, 1948-1970". Habitat International. p. 1-16a. 